\title{
Lactobacillus sp as a Probiotic for the Prevention of Clostridium difficile Associated Diarrhea
}

\section{Ulfa Nur Rohmah, Saskiyanti Ari Andini, Hendrik Prayitno Luawo, Waluyo and Yulia Indah Permata Sari}

Faculty of Nursing, Universitas Airlangga, Surabaya, Indonesia

\section{ABSTRACT}

Background: Antibiotic treatment can disturb the resistance of the gastrointestinal flora to colonization. This may result in complications, the most serious of which is Clostridium difficile associated diarrhea (CDAD). The aim of this study was to determine the effectiveness of probiotics for the prevention of CDAD.

Method: The databases used were Scopus, Proquest, CINAHL, Medline, Pubmed and ScienceDirect, limited to having been published in the last 5 years. A literature review followed the keyword search. The keywords used were probiotics, Clostridium difficile, associated, diarrhea, randomized, control and trial using "AND" and "OR". Twelve trials with 5102 participants were included. Eight trials reported a preventive effect for CDAD using a mixture of 2 strains of lactobacillus, a mixture of 4 combination strains, a mixture of lactobacillus and Saccharomyces or a mixture of Bifidobacterium, Lactobacillus and Saccharomyces.

Result: Our findings indicate that probiotics may prevent CDAD. Most probiotics contain a singular strain. The combination with lactobacillus $s p$ was the most effective at preventing CDAD.

Conclusion: In addition, 6 out of 8 trials had an in relation to preventing CDAD containing lactobacillus sp. Four studies said that there were some factors that meant that the probiotic could not reduce or prevent the CDAD.
\end{abstract}

\section{ARTICLE HISTORY}

Received: Dec 26, 2019

Accepted: Dec 31, 2019

\section{KEYWORDS}

Lactobacillus sp; probiotic; Clostridium difficile; diarrhea

\section{CONTACT}

Ulfa Nur Rohmah

$\triangle$ ulfa.nur.rohmah2018@fkp.unair.ac.id

$\fallingdotseq$ Faculty of Nursing, Universitas Airlangga, Surabaya, Indonesia

Cite this as: Rohmah, U. N, Andini, S.A, Luawo, H.P, Waluyo \& Permatasari, Y.I. (2019). Lactobacillus sp as a Probiotic for the Prevention of Clostridium difficile Associated Diarrhea. Jurnal Ners, 14(3si), 171-176. doi:http://dx.doi.org/10.20473/jn.v14i3(si).17015

\section{INTRODUCTION}

A healthy body normally has Clostridium difficile (CD) bacteria in the intestine. Clostridium difficile (CD) is a Gram positive anaerobic bacterium. The use of antibiotics for an unknown period showed that Clostridium difficile disrupts the colonic microbiata, so then the growth of Clostridium difficile is faster and produces toxins $A$ and $B$. This causes an increase in pseudomembrane colitis with fever and diarrhea (Mizui et al., 2013). The major cause of antibiotic associated diarrhea in hospitals is Clostridium difficile(Li et al., 2018). According this study, the antibiotics used included clindamycin, cephalosporins and fluoroquinolones. The use of these antibiotics is not obligatory (Squellati, 2018). Administering antibiotics as a treatment can interfere with the colonization of the normal flora in the digestive tract, resulting in various symptoms and effects, especially diarrhea. This process results in Clostridium difficile Associated Diarrhea (CDAD)(Li et al., 2018).

Patients who have a sustained Clostridium difficile infection can contract Antibiotic Associated Diarrhea (AAD). It is also known that Clostridium difficile associated diarrhea is a trend that is currently evident, with more than 500,000 people exposed to Clostridium difficile. It may cause major death with inflammation in patients and around $10 \%$ will die (Squellati, 2018). The Centers for Disease Control and Prevention (CDC) conducted a survey about Clostridium difficile in an infection-focused program. There was 34 countries that used 10 sites and other countries showed that CDAD has increased by 453.000 with 29.300 deaths (Approach, 2017) 


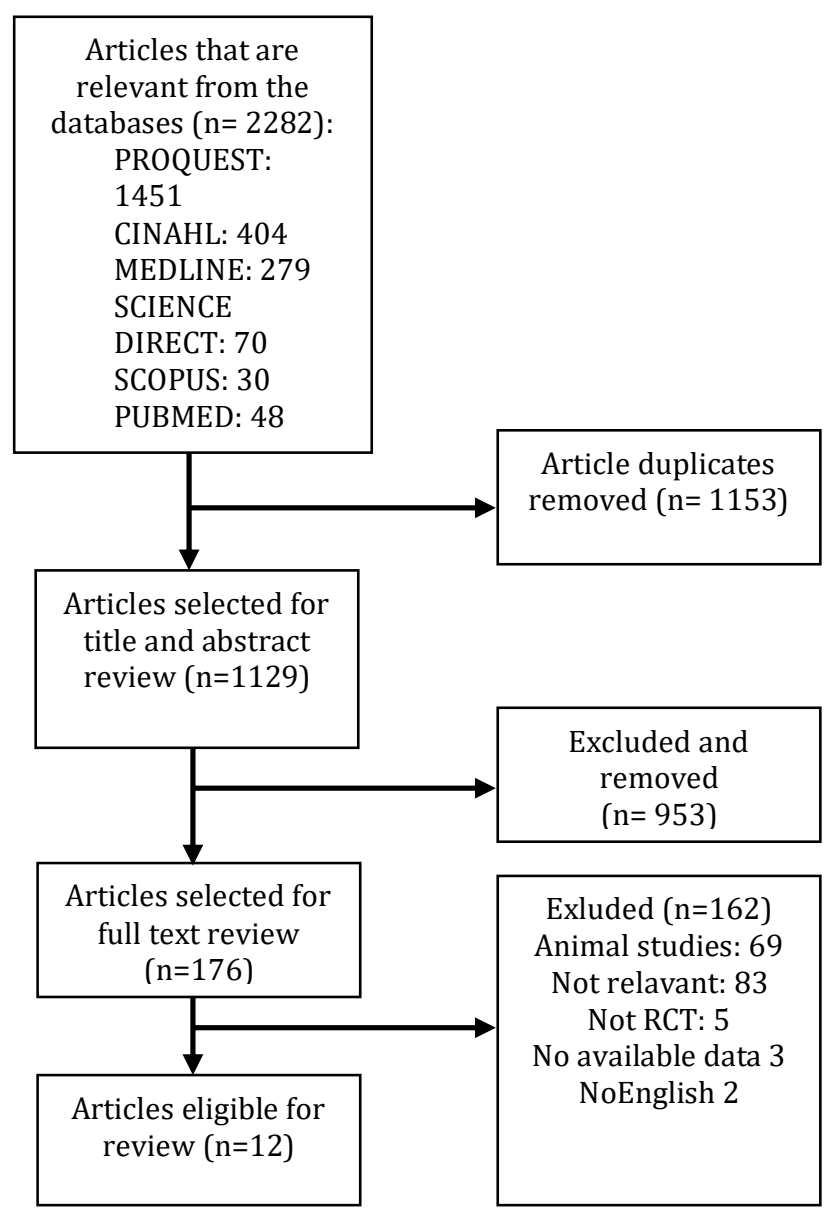

Figure 1. PRISMA Flow Diagram

The complexity of diarrhea generally establishes whether a physician will discontinue or change the antibiotics, and whether a stool specimen needs to be analyzed for the appearance of Clostridium difficile toxins. Other nosocomial infections, long hospital stays, medical care costs, and diagnostic procedures can make the patient at risk for developing AAD (Xie, Li, Wang, Li, \& Chen, 2015).

Probiotics can potentially prevent the development of CDAD and it can make the growth of the normal gastrointestinal flora increased and compensate for the negative microbiota effects of antibiotics. Therefore, probiotics have been greatly used to medicate a variation of conditions influencing the gastrointestinal tract, including diarrhea, inflammatory bowel disease, irritable bowel syndrome, bacterial overgrowth and especially Clostridium difficile infection (Xie et al., 2015). Probiotics also help to take down Clostridium difficile colonization by adhering to the epithelial and mucosal membranes in the colon. But probiotics should not be taken in the ICU, because some patients have an unsuitable reaction as they are already compromised due to the patient's underlying condition (Squellati, 2018).

Probiotics are becoming advanced, existing as capsules and dairy-based food supplements sold in health food stores, medicine stores and on the modern market. If probiotics are effective, then the incidence of Clostridium difficile becomes reduced and adverse events decline, meaning that the cost that the hospital pays is lower. Probiotics make an attractive choice for the prevention of Clostridium difficile associated diarrhea (Johnston et al., 2013). We were guided by systematically reviewing the literature to determine the effectiveness and safety of probiotics (any strain or dose) for the prevention of Clostridium difficile associated diarrhea and looking at the wellbeing of patients who were also receiving antibiotics.

\section{MATERIALS AND METHODS}

\section{Research Design}

The systematic review was used to determine the effectiveness of probiotics for the prevention of CDAD. The use of studies was limited to the latest research, namely for the last 5 years and using the Preferred Reporting Items for Systematic Reviews and Meta-Analyzes (PRISMA) approach.

\section{Search Strategy}

The literature search was carried out focused on several databases such as Scopus, Proquest, CINAHL, Medline, Pubmed and Science Direct. The literature review used the following keywords: probiotics, Clostridium difficile, associated, diarrhea, randomized, control and trial, in addition to using "AND" and the keywords RCT, randomized control and trial using "OR". After a number of articles were obtained, the researcher then selected them again according to the specified inclusion and exclusion criteria.

\section{Inclusion and Exclusion Criteria}

The desired articles were published from 2013 to 2018 , and the age restriction was applied, focusing on the keywords in the search for matching articles. The design method searched for was RCTs that compared interventions based on a variety of strains where a combination of probiotics and doses were eligible. We scanned the lists of identified articles to obtained additional trial articles. Articles with samples that did not focus on humans but that used rats or mice, the discussion of articles outside of the probiotics of Clostridium difficile associated diarrhea, articles with design methods that were not RCT, as well as articles that were systematic reviews, narrative reviews, theses, books or chapters, abstracts and editorials issued in this study were not included according to our exclusion criteria.

\section{Article Searching Process}

The searching of the articles was done using the keyword 'surgical scrubs', 'scrubbing' and 'microorganisms' in accordance with the PICOT method that was determined and we also used the Boolean logic search method on the Ebscho, Science Direct, Springer link, Scopus and ProQuest databases with a time limitation of 2012 - 2018. In the search process, 189 articles were found and 11 articles were in accordance with the inclusion criteria to be 
Table 1 Multi strain or single strain Probiotic Genus

\begin{tabular}{|c|c|c|c|c|c|c|}
\hline Author & $\begin{array}{c}\text { Lactobacillus } \\
s p\end{array}$ & $\begin{array}{c}\text { Bifidobacterium } \\
s p\end{array}$ & $\begin{array}{c}\text { Streptococcus } \\
s p\end{array}$ & $\begin{array}{c}\text { Saccharomyces } \\
\text { sp }\end{array}$ & $\begin{array}{l}\text { Multi } \\
\text { strain }\end{array}$ & $\begin{array}{l}\text { Single } \\
\text { strain }\end{array}$ \\
\hline $\begin{array}{l}\text { (Alberda et al., 2018) } \\
\text { (Allen et al., 2013) } \\
\text { (Barker et al., 2017) } \\
\text { (Chatterjee et al., } \\
\text { 2013) }\end{array}$ & $\begin{array}{l}\sqrt{ } \\
\sqrt{ } \\
\sqrt{ }\end{array}$ & $\begin{array}{l}\sqrt{ } \\
\sqrt{ } \\
\sqrt{ }\end{array}$ & & $\sqrt{ }$ & $\begin{array}{l}\sqrt{ } \\
\sqrt{ } \\
\sqrt{ }\end{array}$ & $\sqrt{ }$ \\
\hline $\begin{array}{l}\text { (Ehrhardt et al., } \\
2016 \text { ) } \\
\text { (Evans et al., 2016) } \\
\text { (Kabbani et al., } \\
\text { 2017) } \\
\text { (Mallina et al., 2018) } \\
\text { (Ouwehand et al., } \\
\text { 2014) } \\
\text { (Selinger et al., 2013) } \\
\text { (Shan et al., 2013) } \\
\text { (Wong et al., 2014) }\end{array}$ & $\begin{array}{l}\sqrt{ } \\
\sqrt{ } \\
\sqrt{ } \\
\sqrt{ } \\
\sqrt{ } \\
\sqrt{ }\end{array}$ & $\begin{array}{l}\sqrt{ } \\
\sqrt{ }\end{array}$ & $\begin{array}{l}\sqrt{ } \\
\sqrt{ }\end{array}$ & $\sqrt{ }$ & $\begin{array}{l}\sqrt{ } \\
\sqrt{ } \\
\sqrt{ }\end{array}$ & $\begin{array}{l}\sqrt{ } \\
\sqrt{ }\end{array}$ \\
\hline
\end{tabular}

explored further. The complete explanation can be seen in Table 1.

\section{RESULTS}

\section{Study Selection and Characteristics}

The initial literature search returned 2282 articles (1451 from PROQUEST, 404 from CINAHL, 279 from MEDLINE, 70 from SCIENCE DIRECT, 30 from SCOPUS, 48 from PUBMED). After reviewing the abstracts for relevance and matching them with the inclusion criteria, 1129 articles were selected for fulltext review and the researcher excluded 953 by title and abstract. There were 176 full text reviews, and then the articles included 29 animal studies; 83 were not relevant, 5 were not RCTs, 5 had no available data, and 2 were in a different language and they were thus excluded. Finally, 12 articles were chosen to review that met the inclusion criteria (Figure 1).

The studies included were homogenous design studies. There were 12 studies that used a randomized control trial design (Table 1). The 12 studies were published between 2013 and 2018. There were 5102 participants across all of the studies and the studies were heterogeneous, with between 32 and 2981 participants per trial with an average sample size of 425 per trial. The age of the participants in the studies ranged between 18 and 70 years. The average age was adult. There were 7 studies that reported on a combination of genuses and 5 studies didn't report what they used. The probiotics which prevented CDAD were from 4 major genuses. There was Lactobacillus sp, Bifidobacterium $s p$, Streptococcus $s p$ and Saccharomyces sp. The probiotics used included from within the Lactobacillus sp genus included Lactobacillus casei, Lactobacillus acidophilus (CUL60, CUL21, LA-5, NFCM), Lactobacillus paracasei (Lpc-37), Lactobacillus helveticus R005, Lactobacillus rhamnosus R0011, Lactobacillus bulgarius and Lactobacillus casei Shirota. The probiotics used that were Bifidobacterium sp included Bifidobacterium bifidium (CUL20, W23), Bifidobacterium lactis (CUL34, Bi-07, B1-04, BB-12), Bifidobacterium breve, Bifidobacterium longum and Bifidobacterium infantis. The probiotics used that were Streptococcus $s p$ included Streptococcus thermophiles and Streptococcus boulardii. The probiotics used that were Saccharomyces sp included Saccharomyces boulardii and Saccharomyces CNCM I-745.

Duration of probiotics giving in this studies was varies, it about from 7 days to several weeks. The doses of the probiotics in the studies varied, and they ranged from a minimum of $1.0 \times 107 \mathrm{cfu}$ to a maximum dose of $6 \times 10_{10}$ cfu. Other preparations include $93 \mathrm{~mL}$, 2 techsules, $250 \mathrm{mg}, 100 \mathrm{gm}(97 \mathrm{~mL})$ and 2 sachets. The duration of the probiotics and antibiotics varied. Diarrhea was defined as consisting of 2 main variations, which were $\geq 3$ loose stools in $24 \mathrm{~h}$ and $\geq$ 2 loose or watery stools per day.

\section{Probiotics Affecting Clostridium Defficile Associated Diarrhea}

A combination probiotic treatment was associated with significant Clostridium defficile associated diarrhea on these studies. Eight trials reported a preventive effect against CDAD with a mixture of Lactobacillus casei and Lactobacillus paracasei CNCM I-1518(Alberda, Marcushamer, Hewer, Journault, \& Demetrios Kutsogiannis, 2018) and a mixture of 4 strains containing Lactobacillus acidophilus NCFM, Lactobacillus paracasei Lpc-37, Bifidobacterium lactis Bi-07 and B. lactis Bl-04(Barker et al., 2017)(Ouwehand et al., 2014). There was also a mixture of Lactobacillus helveticus R0052, Lactobacillus rhamnosus R0011(Evans, Salewski, Christman, Girard, \& Tompkins, 2016) and Saccharomyces boulardii CNCM I-745 (SB) (Kabbani et al., 2017). VSL\#3 contains a mixture of Bifidobacterium breve, Bifidobacterium longum, Bifidobacterium infantis, Lactobacillus acidophilus, Lactobacillus plantarum, Lactobacillus paracasei, Lactobacillus delbrueckii sub.sp., Bulgaricus, 
Streptococcus thermophiles(Selinger et al., 2013), Saccharomyces boulardii(Shan et al., 2013) and Lactobacillus casei Shirota(Wong et al., 2014). Six studies reported that Lactobacillus $s p$ was the most effective probiotic at preventing Clostridium defficile associated diarrhea (Barker et al., 2017)(Barker et al., 2017), (Evans et al., 2016), (Kabbani et al., 2017), (Ouwehand et al., 2014), (Selinger et al., 2013).

Across the 4 trials, it was reported there was no important impact on Clostridium defficile associated diarrhea when using a mixture of 2 strains, namely Lactobacillus acidophilus (CUL600 and CUL21) and two strains of Bifidobacterium (Bifidobacterium bifidum CUL20 and Bifidobacterium lactis CUL34) (Allen et al., 2013). There was also a mixture examined consisting of Lactobacillus acidophilus LA-5 and Bifidobacterium BB-12(Chatterjee et al., 2013), Saccharomyces boulardii(Ehrhardt et al., 2016) and ACTIMEL containing Lactobacillus casei, Lactobacillus bulgaricus and Streptococcus thermophiles (Mallina et al., 2018).

\section{DISCUSSION}

The result of this review found that the age group most affected by CDAD was adults (the youngest being 6 months through to old age in the study overall), although this was not statistically significant. One study stated that being of an age $>18$ years old may increase the risk by about $2 \%$ concerning being infected by Clostiridium defficile in the health care setting. However, the level of infection was neither studied nor evaluated deeply. Old age individuals are more susceptible to Clostridium defficile infection because it is related to their humoral immune response (Patel, Wieczorkiewicz, \& Tuazon, 2016). In addition, CDAD infection often happens at an old age where, in the health care setting, they have consumed broad spectrum antibiotic (Allen et al., 2013).

Based on the review, the duration of consumed probiotics in the studies varied and it was between a minimum of 7 days to a maximum of several weeks. The other studies said that a short treatment duration ( $<8$ weeks) may be more effective than a long duration ( $\geq 8$ weeks) in reference to bowel inflammation. This is related to the quality of the patient's life because longer term or even the continuous supplementation of probiotics may be required to detect significant alterations in the symptoms (Zhang et al., 2016).

We found 4 journals that said that probiotics cannot reduce CDAD. This was found because ineffective probiotic results were related to the limitations of the trial. For example, probiotics that were not according to a doctor's recommended dosage. There were some patients who had not only received probiotics but they had also received a high dosage of antibiotics so the probiotics given at the time no longer have an effect (Box, Ortwine, \& Goicoechea, 2016). Another thing to consider is that the number of study participants was $80.5 \%$ for those not eligible and the patients who were eligible may have been relatively healthy. One must consider a different design for the trial to get better results (Ehrhardt et al., 2016).

On the other hand, our review showed that the probiotics that can reduce CDAD were from 4 different genuses. These were Lactobacillus, Bifidobacterium, Streptococcus and Saccharomyces. It also was explained by Johnston and colleagues. Their systematic review consisted of 20 RCTs with 3818 patients to determine if probiotics are effective at preventing CDAD. They found evidence that shows that probiotics reduce the chance of CDAD to a large extent, with only a small percentage of adverse reactions. The probiotics used were Bifidobacterium, Lactobacillus, Saccharomyces, and Streptococcus(Johnston et al., 2013). It was explained that probiotics are the most effective if given closer to the first antibiotic dose, with a decrement in efficacy for every day of delay in starting probiotics (Shan et al., 2013).

Probiotics Bifidobacterium, Lactobacillus, Saccharomyces, and Streptococcus may have effects that can be attributed to its actions on intestinal immunity. They may improve the number of IgA and other immunoglobulin secreting cells in the intestinal mucosa and it can also stimulate the local release of interferons. It could also function through the advancing of the barrier function, immunomodulation, and competitive adherence to the intestinal mucosa by avoiding or ameliorating various infective or inflammatory diseases (Chatterjee et al., 2013).

On the other hand, this review has shown that Lactobacillus is a great species determinant for the prevention of CDAD. For example, Lactobacillus casei becomes practical when it is flavored. It was shown by Alberda teams (Alberda et al., 2018) said that 32 participants in trial. AAD was documented in $12.5 \%$ of the probiotic Lactobacillus casei drink group and $31.3 \%$ in the control group.

Most of the studies stated that probiotics were more effective against bacterial diarrhea. For instance, when the efficacy of Lactobacillus $G G$ was analyzed in a meta-analysis, as for separate etiologies, it was evident that this probiotic was most effective for rotavirus diarrhea(Guandalini, 2011).

One trial said that Lactobacillus sp strains have been shown to survive passage through the gastrointestinal tract when healthy volunteers were given eubacteriaceae, causing diarrhea. In in-vitro studies, these strains have shown the ability to adhere to human epithelial cells, to maintain the gut barrier and to stimulate an anti-inflammatory response, in addition to blocking pathogen adhesion. It is feasible that these mechanisms have a role in reducing the duration of diarrhea events (Evans et al., 2016).

Lactobacillus can also reduce CDAD according to Ouwehand et al. as seen in a trial. Their result showed there to be a significant dose response effect in CDAD with an incidence of $12.5,19.6$, and 24.6 with the high dose, low dose and placebo $(\mathrm{p}=0.02)$. They said that abdominal pain was reduced only in the high-dose 
group, focusing on the diarrhea cases. Only the lowdose group showed a trend for reduced abdominal pain. This reduction in pain is interesting, as $L$. acidophilus NCFM, one probiotic out of the components in the tested preparation shown earlier, was shown been able to increase the pain threshold in rats by inducing the expression of the $\mu$ opioid and canabinoid 2 receptor numbers. Both the average of the liquid stools and the average duration of the diarrhea were significantly reduced by both the high and low doses compared to the placebo (Ouwehand et al., 2014). The other study said that the average of the probiotics containing Lactobacillus sp. had a preventive effect on CDAD, with a pooled relative risk reduction of 75 (Sinclair, Xie, Saab, \& Dendukuri, 2016).

The limitation in this study was that statistical evidence was not provided to support the recommendations for the routine using of microbial preparations for CDAD prevention. The most effective probiotics preparations or probiotic forms to prevent CDAD still need to be investigated.

\section{CONCLUSION}

This systematic review was used to determine the effectiveness of probiotics at preventing CDAD. Our findings indicate that probiotics may prevent CDAD. Most probiotics contain a singular strain, but it was the one that was in combination with Lactobacillus $s p$ that was the most effective at preventing CDAD. In total, 6 out of 8 trials showed as having an effective effect when it comes to preventing CDAD containing Lactobacillus sp. Four studies said that there were some factors that meant that the probiotic cannot reduce or prevent $\mathrm{CDAD}$ : this includes giving probiotics that are not according to the Doctor's recommended dosage and not only consuming the probiotic but also high dosages of antibiotics.

\section{NURSING IMPLICATION}

The results of the review of many studies can be implicated in providing help to prevent CDAD through the use of probiotics. The nurses can provide an intervention and structured management education for the patients in hospital or in a home care setting about using the right antibiotic, using probiotics and creating a comfortable and clean environment in both a hospital and home care setting.

\section{REFERENCES}

Alberda, C., Marcushamer, S., Hewer, T., Journault, N., \& Demetrios Kutsogiannis. (2018). Feasibility of a Lactobacillus casei Drink in the Intensive Care Unit for Prevention of Antibiotic Associated Diarrhea and Clostridium difficile. https://doi.org/10.3390/nu10050539

Allen, S. J., Wareham, K., Wang, D., Bradley, C., Hutchings, H., Harris, W., ... Mack, D. (2013).
Lactobacilli and bifi dobacteria in the prevention of antibiotic-associated diarrhoea and Clostridium diffi cile diarrhoea in older inpatients (PLACIDE): a randomised, double-blind, placebo-controlled, multicentre trial. The Lancet, 6736(Cdd), 1-9. https://doi.org/10.1016/S0140-6736(13)612180

Approach, E. (2017). Clinical update. 13(4), 238-241.

Barker, A. K., Duster, M., Valentine, S., Hess, T., Archbald-pannone, L., \& Guerrant, R. (2017). A randomized controlled trial of probiotics for Clostridium difficile infection in adults ( PICO ). (August), 3177-3180. https://doi.org/10.1093/jac/dkx254

Box, M. J., Ortwine, K. N., \& Goicoechea, M. (2016). No Impact of Probiotics to Reduce Clostridium difficile Infection in Hospitalized Patients: A Real-world Experience. (Table 1), 9-11. https://doi.org/10.1093/ofid/ofy192

Chatterjee, S., Kar, P., Das, T., Ray, S., Ganguly, S., Rajendiran, C., \& Mitra, M. (2013). Randomised Placebo-controlled Double Blind Multicentric Trial on Efficacy and Safety of Lactobacillus acidophilus $L A-5 \AA$ and Bifidobacterium BB-12 $₫$ for Prevention of Antibiotic-Associated Diarrhoea. 61(october), 708-712.

Ehrhardt, S., Guo, N., Hinz, R., Schoppen, S., May, J., Reiser, M., ... Lohse, A. W. (2016). Saccharomyces boulardii to Prevent Antibiotic-Associated Diarrhea: A Randomized, Double-Masked, PlaceboControlled Tria. 1-7. https://doi.org/10.1093/ofid/ofw011

Evans, M., Salewski, R. P., Christman, M. C., Girard, S., \& Tompkins, T. A. (2016). Effectiveness of Lactobacillus helveticus and Lactobacillus rhamnosus for the management of antibioticassociated diarrhoea in healthy adults: a randomised, double-blind, placebo-controlled trial. 94-103. https://doi.org/10.1017/S0007114516001665

Guandalini, S. (2011). Probiotics for Prevention and Treatment of Diarrhea. 45(December), 149-153.

Johnston, B. C., Stephanie S.Y. Ma, M., Z, J., Goldenberg, Bs., Kristian Thorlund, P., Per O. Vandvik, MD, P., ... Gordon H. Guyatt, M. (2013). Review Annals of Internal Medicine Probiotics for the Prevention of Clostridium difficile - Associated. (20).

Kabbani, T. A., Pallav, K., Dowd, S. E., Villafuertegalvez, J., Vanga, R. R., Castillo, N. E., ... Kelly, C. P. (2017). Prospective randomized controlled study on the effects of Saccharomyces boulardii CNCM I745 and amoxicillin-clavulanate or the combination on the gut microbiota of healthy volunteers. 0976. https://doi.org/10.1080/19490976.2016.12678 90

Li, N., Zheng, B., Cai, H., Chen, Y., Qiu, M., Liu, M., ... Mb, L. (2018). Accepted Manuscript. https://doi.org/10.1016/j.jhin.2018.04.013

Mallina, R., Frcs, J. C., Frcs, N. B., Ahluwalia, V., Frcp, J. C., \& Frcs, A. G. C. (2018). Journal of Infection and Public Health Probiotic containing Lactobacillus 
casei , Lactobacillus bulgaricus, and Streptococcus thermophiles ( ACTIMEL ) for the prevention of Clostridium difficile associated diarrhoea in the elderly with proximal femur fractures. Journal of Infection and Public Health, 11(1), 85-88. https://doi.org/10.1016/j.jiph.2017.04.001

Mizui, T., Teramachi, H., Tachi, T., Tamura, K., Shiga, H., Komada, N., ... Aoyama, S. (2013). Risk factors for Clostridium difficile -associated diarrhea and the effectiveness of prophylactic probiotic therapy. 68. https://doi.org/10.1691/ph.2013.3552

Ouwehand, A. C., Donglian, C., Weijian, X., Stewart, M., Ni, J., Stewart, T., \& Miller, L. E. (2014). Probiotics reduce symptoms of antibiotic use in a hospital setting: A randomized dose response study. Vaccine, 32(4), 458-463. https://doi.org/10.1016/j.vaccine.2013.11.053

Patel, U. C., Wieczorkiewicz, J. T., \& Tuazon, J. (2016). Journal of Clinical Gerontology \& Geriatrics Evaluation of advanced age as a risk factor for severe Clostridium dif fi cile infection. Journal of Clinical Gerontology \& Geriatics, 7(1), 12-16. https://doi.org/10.1016/j.jcgg.2015.06.003

Selinger, C. P., Bell, A., Cairns, A., Lockett, M., Sebastian, S., \& Haslam, N. (2013). Probiotic VSL \# 3 prevents antibiotic-associated diarrhoea in a double-blind, randomized, placebo- controlled clinical trial. Journal of Hospital Infection, 84(2), 159-165. https://doi.org/10.1016/j.jhin.2013.02.019

Shan, L., Hou, P., Wang, Z., Liu, F., Chen, N., Shu, L., ... Shang, Y. (2013). Prevention and treatment of diarrhoea with Saccharomyces boulardii in children with acute lower respiratory tract infections. 4(December), 329-334. https://doi.org/10.3920/BM2013.0008
Sinclair, A., Xie, X., Saab, L., \& Dendukuri, N. (2016). Lactobacillus probiotics in the prevention of diarrhea associated with Clostridium difficile: a systematic review and Bayesian hierarchical metaanalysis. 4(4), 706-714. https://doi.org/10.9778/cmajo.20160087

Squellati, R. (2018). Evid e $n c e-B$ a s ed Pr a c t i c $e$ i $n t$ he Tre atm en $t$ for Antibiotic-Associated Diarrhea in the I ntensive Care Unit. 30, 87-99. https://doi.org/10.1016/j.cnc.2017.10.008

Wong, S., Jamous, A., Driscoll, J. O., Sekhar, R., Weldon, M., Yau, C. Y., ... Forbes, A. (2014). A Lactobacillus casei Shirota probiotic drink reduces antibioticassociated diarrhoea in patients with spinal cord injuries: a randomised controlled trial British Journal of Nutrition. 672-678. https://doi.org/10.1017/S0007114513002973

Xie, C., Li, J., Wang, K., Li, Q., \& Chen, D. (2015). ScienceDirect Probiotics for the prevention of antibiotic- associated diarrhoea in older patients : A systematic review. Travel Medicine and Infectious Disease, 1-7. https://doi.org/10.1016/j.tmaid.2015.03.001

Zhang, Y., Li, L., Guo, C., Mu, D., Feng, B., Zuo, X., \& Li, Y. (2016). Effects of probiotic type, dose and treatment duration on irritable bowel syndrome diagnosed by Rome III criteria: a. $B M C$ Gastroenterology, 1-11. https://doi.org/10.1186/s12876-016-0470-z 